obtained while consents were taken from students and their families. Data were collected with Individual Information Form, Traditional Peer Bullying Scale with a face-to-face interview and analysed with descriptive statistics and chi-square test on computer.

Findings It was determined that mean age of the students was $12.81 \pm 0.93$ years, of them $51.7 \%$ were girls, $12.0 \%$ did bullying and $15.9 \%$ were exposed to bullying (victim) while $15.1 \%$ were both bully/victim. Boys and 8th graders were found to bully more than girls ( $\mathrm{p}^{\text {th }}$ and 7 th graders, respectively $\left(\mathrm{p}^{\text {th }}\right.$ grade and with a moderate level of economic status were found to be exposed to bullying more than 7 th and 8 th graders ( 0.05 ).

Conclusion and recommendations Consequently, bullying at schools is a serious problem and programs including students, teachers and parents about preventing bullying should be developed and generalised.

\section{PO-0877 THE EFFECT OF PERCEIVED EMOTIONAL ABUSE ON SOCIAL SKILLS IN INTERMEDIATE GRADE STUDENTS}

${ }^{1} \mathrm{M}$ Kurtuncu, ${ }^{2} \mathrm{C}$ Yigitbas, ${ }^{3} \mathrm{~L}$ Utas Akhan, ${ }^{3} \mathrm{~S}$ Celik, ${ }^{1} \mathrm{I}$ Alkan, ${ }^{4} \mathrm{I}$ Tanir. ${ }^{1}$ Pediatric Nursing, Bulent Ecevit University, Zonguldak, Turkey; ${ }^{2}$ Nursing, Gumushane University, Gumushane, Turkey; ${ }^{3}$ Psychiatry Nursing, Bulent Ecevit University, Zonguldak, Turkey; ${ }^{4}$ Medical Doctor, Sultanbeyli State Hospital, Istanbul, Turkey

\subsection{6/archdischild-2014-307384.1500}

Background and aims Although there is an increase in studies regarding child abuse and neglect, with studies on physical and sexual abuse taking lead, in the last ten years, there are very little studies on the long term effects of behaviour in schools that include emotional abuse. The attitudes and efforts of parents and teachers are very important in preventing such problems. The purpose of this study is to determine the effects of perceived emotional abuse the children receive from parents and teachers on social skills in intermediate grade students.

Methods The design of the study is descriptive. The cross sectional study was conducted with students in the 10-15 age category studying in two middle schools in Turkey between February-June 2013. The selection of the schools was determined by the reachable sample method. There was no sample selection in the study, and all of the students in the universe ( $\mathrm{n}$ $=753$ ) were included in the sample.

Results It was also found in the study that there was an advanced relationship between the gender variable and the positive social behaviour score averages $(\mathrm{p}=0.000)$, and that male students had a higher positive behaviour score average than female students. As it can be seen in Table 1, children took scores below average only from the MESSY scale, while their scores from the other three scales were above average.

Conclusions There is a significant relationship between the social skill levels of children aged between 10-15 years and perceived emotional abuse by parents.

Abstract P0-0877 Table 1 Distributions of the MESSY, MTRS, FTRS, and PTBS Scale Score Averages of the Students (N:753)

\begin{tabular}{llll}
\hline Scales & $\mathbf{X} \pm$ SD & Min. & Max. \\
\hline MESSY & $136.90 \pm 14.45$ & 63.00 & 213.00 \\
MTRS & $352.50 \pm 42.48$ & 100.00 & 401.00 \\
FTRS & $362.89 \pm 46.51$ & 100.00 & 400.00 \\
PTBS & $183.31 \pm 24.92$ & 60.00 & 242.00 \\
\hline
\end{tabular}

The Matson Evaluation Scale for Social Skills in Younger People (MESSY).

The Perceived Teacher Behaviour Scale (PTBS).

The Mother/Father-Teenager Relationships Scale (MTRS/ FTRS).

\section{PO-0878 ADHERENCE OF THE HEALTH CARE PRACTITIONERS TO THE ADOLESCENT REPRODUCTIVE HEALTH AND DEVELOPMENT POLICY AT THE GARISSA PROVINCIAL GENERAL HOSPITAL, KENYA}

CM Musee. Nursing, Kenyatta National Hospital, Machakos, Kenya

\subsection{6/archdischild-2014-307384.1501}

Background Kenya's policies on population, family planning (FP) and reproductive health (RH) often receive weak adherence. This undermines their implementation. The youth form the majority of the Kenyan population. The Adolescent $\mathrm{RH}$ and Development (ARH\&D) policy, formulated in 2003, gives direction on meeting reproductive and developmental needs of the youth.

Methods The research done in June 2012, was hospital based, cross sectional, with qualitative and quantitative aspects. Research instruments included questionnaires, check lists and key informant interviews. The sample size comprised of 119 HCPs chosen randomly and 53 adolescent clients sampled purposively.

Data analysis was done using the statistical package of social scientists (SPSS) computer. Inferential statistics were done by chi square and Fisher's exact to compare percentages and association between adherence to the ARH\&D policy and HCP characteristics.

Results The HCP adherence rate to the ARH\&D was $62.2 \%$ while the adolescent client $\mathrm{RH}$ service satisfaction was about 94\%. Adherence was higher among HCPs that were younger ( $p$ $=0.005)$, Christians $(\mathrm{p}=0.006)$, and those supervised frequently ( $p=0.047$ ). Severity of infibulation has reduced among the Somali but is still at grade 4 among the Malakote. Consanguineous marriages, drug addiction, poverty are common. HIV and AIDS and FP stigmatisation is high.

Conclusion Adherence to the ARH and D policy, which was about $60 \%$, was influenced by frequency of staff supervision, religious affiliation and the age the HCPs. Client satisfaction level was about 34\%.

\section{PO-0879 IMPACT OF UNIVERSITY STUDENTS' USE OF SOCIAL MEDIA ON THEIR LEVEL OF LONELINESS AND ANXIETY}

${ }^{1} \mathrm{~L}$ Utas akahn, ${ }^{2} \mathrm{M}$ Kurtuncu. ${ }^{1}$ Psychiatric Nursing, Bulent Ecevit University, Zonguldak, Turkey; ${ }^{2}$ Pediatric Nursing, Bulent Ecevit University, Zonguldak, Turkey

10.1136/archdischild-2014-307384.1502

Background and aims Along with the many conveniences introduced into our lives by use of the computer and internet, there are also many problems associated with the excessively frequent use of them. According to Rehm, the internet is a means for individuals to redefine themselves both individually and socially in several aspects including among others education, health, child development, dialogue, intercommunication, self-fulfilment, but can also be the cause of reduced social communication as well as social deviations. The longer time the internet is used, 
the less enter the users into relationship with people in social life; which may result in "social isolation".

This research was carried out in the form of a descriptive study aimed to identify the impact of university students' use of social media on their level of loneliness and anxiety.

Methods The universe of research consisted of 754 students of a state university, willing to participate in research. In the personal data sheet developed for the purpose of data gathering, the researchers made use of the Beck Anxiety Inventory and UCLA Loneliness Scale. The researchers obtained written permits form the state university's ethics committee as well as written and verbal consent forms from participating students.

Conclusion The results revealed that $65.1 \%$ of the participants had an own personal computer, $60.7 \%$ had a Facebook account, $14.5 \%$ a Twitter account, $37.4 \%$ spent $1-2 \mathrm{~h}$ on the computer, while $18.6 \%$ spent $3-4 \mathrm{~h}$; and that $31.6 \%$ used the internet to get information, $11 \%$ to get socialised/establish friendships, $27.6 \%$ to get rid of boredom, and $32.2 \%$ to engage in conversation.

Discussion The loneliness level of students making use of social media $8 \mathrm{~h}$ a day or more, the anxiety level of students making use of social media almost never/only once in a month or those staying with their relatives, and the anxiety and loneliness level of those at an age of 31 and more have been found to be high.

\section{Nursing - Hematology and Oncology}

\section{PO-0880 EVALUATION OF MUCOSITIS IN PAEDIATRIC ONCOLOGY PATIENTS}

E Efe, SULE Senol. Nursing Faculty, Akdeniz University, Antalya, Turkey

\subsection{6/archdischild-2014-307384.1503}

Background Cancer is a disease that is also encountered in children and requires an intensive treatment process. Chemotherapy medications and radiotherapy also harm healthy mucosa cells and cause mucositis while destroying malign cells.

Aim Evaluation of mucositis in paediatric oncology patients.

Method Review of the studies conducted on this field.

Result Children have difficulty in eating and drinking, and may refuse to eat due to pain, bleeding, ulceration, xerostomia, changes in the taste and malnutrition experienced during mucositis. Evaluation of mucositis is difficult due to their inability to cooperate for evaluation because of their young ages, the need for fast and easily-applied rating scale special to children, and the needs of the medical personnel and family to be trained about mucositis. World Health Organisation's rating can be used in evaluation of mucositis. This is a simple rating scale, can be used for young children, and takes a short time to use. Another evaluation scale is developed by National Cancer Institute. In this scale; effect of symptoms and findings of mucositis are determined on functions such as eating and rating is performed. "Oral Health Evaluation Guide" assessing other structures inside the mouth can also be used. This scale is modified for child and parents. Another scale is Children's International Mucositis Evaluation Scale.

Conclusion It is recommended for healthcare organisations to perform the evaluation of mucositis by using comprehensible scales before and after the treatment. Damages of mucositis can be prevented or reduced by considering these recommendations and scales.

\section{P0-0881 THE EFFECT OF FAMILY CENTRED CARE ON THE ANXIETY LEVELS OF CHILDREN WITH CANCER AND PARENTS}

${ }^{1} \mathrm{U}$ Gunay, ${ }^{2} \mathrm{~S}$ Polat. ${ }^{1} N$ ursing, Inönü University School of Healthy, Malatya, Turkey; ${ }^{2}$ Nursing, Bozok University School of Healthy, Yozgat, Turkey

\subsection{6/archdischild-2014-307384.1504}

Introduction This research was carried out in order to determine the effect of family centred care on the anxiety levels of children with cancer and parents.

Methods The study was carried out in the child oncology clinic of a university hospital between March 2011 and April 2013. The study sample consisted of 33 children, their mothers, and 12 fathers as the study group and 31 children, their mothers, and 10 fathers as the control group. Furthermore, the study consisted 11 nurses and 4 physicians who are employed in the clinic. The data were collected using a Descriptive Questionnaire for Parents and Children, the Family-Centred Care Questionnaire, State-Trait Anxiety Inventory. The scales were administered to the study and control groups 3 times, once at the first meeting and then in monthly intervals. All data was analysed using SPSS.

Results No difference was found during the first measurement between the mean state-trait anxiety scores of the children and parents in the study and control groups. Following the familycentred care training given to the health professionals, the mean state-trait anxiety scores of the children and parents in the study group showed a significant decrease in the last measurements as compared to the control group $(\mathrm{p}<0.001)$.

Conclusion The study revealed that the family-centred care was effective in reducing the anxiety levels of children with cancer and parents. Thus, we recommend that the practice of familycentred care be proliferated.

\section{P0-0882 DETERMINING THE BURDEN LOAD AND THE LIFE QUALITY OF THE MOTHER AND FATHERS OF THE CHILDREN WITH CANCER DIAGNOSIS AND HEMATOLOGIC DISEASES}

${ }^{1} S$ Yavuz, ${ }^{2}$ D Yildiz. 'Department of Pediatric, Turkish Armed Forces Diyarbakir Military Hospital, Diyarbakir, Turkey; ${ }^{2}$ Department of Pediatric, Gulhane Military Medical Academy School of Nursing, Ankara, Turkey

\subsection{6/archdischild-2014-307384.1505}

This research was planned as descriptive study for thepurpose of determining the burden load and the life quality of the mother andfathers of the children with cancer diagnosis and hematologic diseases.

Methods The research was carried out in the PediatricsHematology and Oncology Polyclinic and Clinics of Gulhane Military Medical Academy,between December 2011-April 2012. The research sample was composed of 101parents of children with cancer diagnosis and hematologic diseases.

The questionnaire form that was prepared by theresearcher, "Caregiving Burden Scale" and "Rolls Royce Life Quality Scale" wereapplied to participants.

Results It was determined that the score of careburden of the parents who are in 46-55 age group, who have three and 